\title{
Theory of mind in schizophrenia and bipolar disorder: Psychometric properties of the Norwegian version of the Hinting Task
}

\author{
Mathias Frøyhaug a, Stein Andersson ${ }^{\text {b }}$, Ole A. Andreassen ${ }^{\text {a, c }}$, \\ Torill Ueland ${ }^{\mathrm{a}, \mathrm{b}}$, Anja Vaskinn a, c, *
}

${ }^{a}$ Norwegian Centre for Mental Disorders Research, Oslo University Hospital, Oslo, Norway,

${ }^{b}$ Department of Psychology, University of Oslo, Oslo, Norway, ${ }^{c}$ Institute of Clinical Medicine, University of Oslo, Oslo, Norway

*anja.vaskinn@medisin.uio.no

ORCIDs:

Stein Andersson: 0000-0002-7556-7621

Ole A. Andreassen: 0000-0002-4461-3568

Anja Vaskinn: 0000-0003-0339-6170 


\title{
THE NORWEGIAN HINTING TASK
}

\begin{abstract}
Introduction: The quality of measures used to assess theory of mind (ToM) in severe mental illness has not been sufficiently investigated. This study evaluated the psychometric properties of the Norwegian version of the Hinting Task in schizophrenia, bipolar I and II disorder and healthy controls.
\end{abstract}

Methods: The study included 90 patients and 183 healthy controls. Internal consistency, ceiling effects, discriminatory power and concurrent and construct validity were investigated.

Results: The Hinting Task displayed adequate levels of internal consistency for schizophrenia and bipolar I disorder. Ceiling effects emerged in all groups except the schizophrenia group. Schizophrenia patients scored significantly lower than all other groups, but no other significant group differences were detected. In the schizophrenia group, the Hinting Task's concurrent validity was substantiated by significant correlations with measures of neurocognition, symptoms and functional capacity. In the bipolar disorder groups, however, only a few significant relationships were found. Correlations between the Hinting Task and a measure of emotion recognition indicated that construct validity was higher for schizophrenia than bipolar disorder.

Conclusions: The results suggest that the Norwegian Hinting Task is suited for use in schizophrenia research and assessment, but caution is warranted when using the test for other populations.

Keywords: theory of mind; psychometrics; schizophrenia; bipolar disorder; Hinting Task 


\section{THE NORWEGIAN HINTING TASK}

\section{Introduction}

Theory of mind (ToM) is a social cognitive domain often defined as the capacity to infer and interpret the mental states of others (Brüne \& Brüne-Cohrs, 2006). There is a marked difference in ToM performance between schizophrenia patients and healthy controls (Bora, Yucel, \& Pantelis, 2009; Savla et al., 2013; Sprong et al., 2007), and impaired ToM is related to levels of negative and disorganized symptoms of schizophrenia (Ventura, Wood, \& Hellemann, 2013). ToM impairment is also significantly negatively correlated with community functioning in schizophrenia. This relationship is stronger than those between functioning and other social cognitive domains such as emotion recognition or social perception (Fett et al., 2011). ToM deficits have also been reported in bipolar disorder (BD; Bora, Bartholomeusz, \& Pantelis, 2016; Samamé, Martino, \& Strejilevich, 2015), although this group is less impaired than the schizophrenia group (Bora \& Pantelis, 2016). For BD, ToM deficits are more consistently reported than other social cognitive impairments. A metaanalysis identified ToM impairments across measures and clinical states in BD patients (Bora et al., 2016). Both mania and bipolar depression have been linked to more pronounced ToM deficits compared to euthymia (Bodnar \& Rybakowski, 2017; Bora et al., 2016; Hawken et al., 2016; Ioannidi, Konstantakopoulos, Sakkas, \& Oulis, 2015). Significant correlations between ToM and functional outcome in BD have only been reported in a minority of studies examining this relationship (Vlad et al., 2018). Comparisons of ToM deficits between schizophrenia and BD are motivated by overlaps in symptoms and genetic basis, in addition to the possible role of ToM impairment as an endophenotype of the psychoses (Mitchell \& Young, 2016).

Several tests have been developed for the study of ToM in severe mental illness. Their psychometric properties are not always known, and the validity of findings is therefore uncertain. The Social Cognition Psychometric Evaluation (SCOPE) initiative addressed some 


\section{THE NORWEGIAN HINTING TASK}

of these issues for schizophrenia (Pinkham et al., 2014). Three ToM measures were included: Reading the Mind in the Eyes Test (RMET; Baron-Cohen, Wheelwright, Hill, Raste, \& Plumb, 2001), The Awareness of Social Inferences Test (TASIT) - Part III (McDonald, Flanagan, Rollins, \& Kinch, 2003) and the Hinting Task (Corcoran, Mercer, \& Frith, 1995). The Hinting Task, a measure of indirect speech comprehension, displayed the strongest psychometric properties (Pinkham, Harvey, \& Penn, 2018; Pinkham, Penn, Green, \& Harvey, 2016): acceptable levels of internal consistency, significant case-control differences and significant associations with measures of functioning. No clear ceiling effects emerged, but several other authors have noted a vulnerability to ceiling effects (Davidson, Lesser, Parente, \& Fiszdon, 2017; Green et al., 2008; Roberts \& Penn, 2009). Although the Hinting Task has been translated to several languages and is used in several countries, the psychometric properties of translated versions are largely unexplored. Additionally, most of the psychometric research has been done with chronic schizophrenia patients (Pinkham et al., 2016, 2018) or patients with first-episode psychosis (FEP; Ludwig, Pinkham, Harvey, Kelsven, \& Penn, 2017, Mallawaarachchi, Cotton, Anderson, Killackey, \& Allott, 2019) and little is known regarding the performance of both the original and translated versions in BDonly groups. Studies of translated versions can inform us of a test's validity in another cultural setting. For the topic of this paper, the Norwegian version of the Hinting Task, we expected similar psychometrics to existing versions as Norway is similar to other Western countries. Finally, investigations of the construct validity (convergent and discriminant validity) of the Hinting task are scarce. In a recent psychometric FEP study of the Hinting Task, Mallawaarachchi et al. (2019) reported relatively low convergent validity and moderate discriminant validity. 


\section{THE NORWEGIAN HINTING TASK}

The current study investigates the psychometric properties of the Norwegian translation of the Hinting Task for patients with schizophrenia, bipolar I disorder (BD-I) or bipolar II disorder (BD-II) and healthy controls. We have three objectives:

(1) To examine the internal consistency and ceiling effects of the Norwegian version of the Hinting Task across clinical and healthy control groups.

(2) To investigate the Norwegian version of the Hinting Task's ability to discriminate between schizophrenia, BD-I, BD-II and healthy control groups.

(3) To examine the relationship between the Norwegian version of the Hinting Task and criterion measures of emotion recognition (construct validity), neurocognition, symptoms and functional outcome (concurrent validity). In all three clinical groups, the Hinting Task was expected to be significantly correlated with emotion recognition and neurocognition. Significant correlations with disorganized and negative symptoms in the schizophrenia group and manic and depressive symptoms in the BD groups were also expected. Finally, we anticipated that the Hinting Task would be significantly correlated with measures of functional capacity and social functioning in the schizophrenia group. No predictions were formulated for explored associations between ToM and functioning in the BD groups, given conflicting results from previous research.

\section{Methods}

\subsection{Participants}

Ninety patients with severe mental illness were recruited from psychiatric units at hospitals in the Oslo region of Norway. With the exception of one participant, all received outpatient care. The distribution of DMS-IV (American Psychiatric Association, 2000) diagnoses was as follows: schizophrenia $=25$, schizoaffective disorder $=5, \mathrm{BD}-\mathrm{I}=31$ and BD-II $=29$. Patients with schizophrenia and schizoaffective disorder were grouped together. Diagnoses were based 


\section{THE NORWEGIAN HINTING TASK}

on the Structured Clinical Interview for DSM-IV (SCID-I; First, Spitzer, Gibbon, \& Williams, 1997) conducted by trained psychologists/psychiatrists $(k=0.77,95 \%$ CI 0.60 0.94). One hundred and eighty-three healthy participants from the same geographic area were randomly selected from national statistical records and recruited via letters. Inclusion criteria included Norwegian (or another Scandinavian language) as first language and/or all compulsory schooling in Norwegian, age between 18 and 65, no history of head trauma that required hospitalization or neurological disorder and IQ above 70. Current IQ was estimated with the two-subtest version of the Wechsler Abbreviated Scale of Intelligence (WASI; Wechsler, 2007). In addition, healthy control participants were excluded if they or a firstdegree relative had a history of severe mental illness, or if they presented with a current substance abuse disorder. Demographic characteristics are presented in Table 1. All participants were part of the Thematically Organized Psychosis (TOP) study at the Norwegian Centre for Mental Disorders Research (NORMENT). The study was approved by the Regional Committee for Medical and Health Research Ethics and the Norwegian Data Inspectorate. A complete description of the study was provided to all participants before giving written informed consent.

\subsection{Social cognitive measures}

The Hinting Task (Corcoran, Mercer, \& Frith, 1995) was designed to assess the ability of patients with schizophrenia to understand the true intent of indirect speech. It consists of 10 written vignettes read out loud by the administrator. Each vignette describes a brief interaction between two characters and concludes with one of them suggesting something in indirect speech (dropping a hint). The participant is asked to answer a question about the character's intentions. The maximum score is 20 , lower scores representing more impaired ToM. The translation of the Hinting Task was carried out by a Norwegian expert on social 


\section{THE NORWEGIAN HINTING TASK}

cognition, then back-translated by a cognition expert fluent in both Norwegian and English. It has been approved as the official Norwegian version.

Emotion recognition was measured with Pictures of Facial Affect (PFA; Frommann, Streit, \& Wölwer, 2003). It contains 28 photographs of faces and requires the participant to judge which basic emotion (happiness, anger, fear, sadness, surprise, disgust, neutral) is expressed. PFA is scored as percent correct answers.

\subsection{Neurocognitive measures}

Neurocognition was assessed with the Norwegian version of the MATRICS Consensus Cognitive Battery (MCCB; Nuechterlein et al., 2004), minus the social cognitive subtest. It was excluded as previous Norwegian research indicated that it failed to detect social cognitive impairment in schizophrenia (Holmén et al., 2010). A mean neurocognitive composite score was computed based on T-scores of the seven remaining tests. Two patients had a missing score on one MCCB subtest. For these participants the respective group means were inserted.

\subsection{Symptom measures}

Psychotic symptoms were assessed with The Positive and Negative Syndrome Scale (PANSS) for Schizophrenia (Kay et al., 1987). The five-factor PANSS model by Wallwork, Fortgang, Hashimoto, Weinberger, \& Dickinson (2012) was used. One patient with schizophrenia had missing scores on two PANSS items. The mean item scores of the schizophrenia group were inserted before the factor scores was computed. Depressive symptoms were measured with the Calgary Depression Scale for Schizophrenia (CDSS; Addington, Addington, \& Schissel, 1990). Manic symptoms were measured with the Young Mania Rating Scale (YMRS; Young et al., 1978). One participant with BD-I had a missing score on item 2 of the YMRS, hence the BD-I group mean was inserted.

\subsection{Functional measures}




\section{THE NORWEGIAN HINTING TASK}

Attainment-based social functioning was assessed with the Social Functioning Scale (SFS;

Birchwood, Smith, Cochrane, Wetton, \& Copestake, 1990), a 76-item self-report

questionnaire measuring seven components of social functioning. The Norwegian SFS,

validated for both schizophrenia and BD (Hellvin et al., 2010), was used. A mean composite score was computed based on the seven subscores. One participant in the BD-II group had a missing score on one subscale, and the mean of the BD-II group was inserted. Non-social functional capacity was measured with the Brief University of California San Diego (UCSD) Performance-based Skills Assessment (UPSA-B; Mausbach, Harvey, Goldman, Jeste, \& Patterson, 2006). UPSA-B contains two subscales (finance and communication), and the functional capacity of participants is assessed through role-play. In the current study the total score (0-100) of UPSA-B was used. SFS was administered to all participants, while UPSA-B was only administered to patients due to an anticipated ceiling effect in the healthy control group.

\subsection{Statistical analyses}

All statistical analyses were performed using The Statistical Package for the Social Sciences version 25 (SPSS, Inc., Chicago, IL, USA). Variables were checked for normality with the Kolmogorov-Smirnov test, skewness and kurtosis statistics and visual inspection of histograms and Q-Q-plots. Most variables were non-normally distributed in at least one of the three clinical groups. The distribution of the Hinting Task variable was particularly skewed (skewness [SE]/kurtosis [SE]: schizophrenia $=-1.48$ [0.43]/2.46 [0.83], BD-I $=-1.48$ $[0.42] / 2.17[0.82], \mathrm{BD}-\mathrm{II}=-0.75[0.43] /-0.50[0.85]$, healthy controls $=-1.14[0.18] / 1.85$ [0.36]), with a large number of high scores across groups. Cronbach's $\alpha$ was used to evaluate internal consistency of the Hinting Task. Additionally, score frequencies on the Hinting Task were examined for ceiling effects. To compare the performance of the clinical and healthy control groups on the Hinting Task, the non-parametric Kruskal-Wallis test was used, 


\section{THE NORWEGIAN HINTING TASK}

followed up by pairwise comparisons with Bonferroni corrected $p$-values when significant main effects were detected. The effect size $r(z / \sqrt{ } \mathrm{N})$ was calculated for all non-parametric comparisons (Durlak, 2009; Field, 2013). ANOVAs, Kruskal-Wallis tests and chi-square tests were used to compare groups on demographic, clinical, cognitive and functional measures. Concerning the investigation of construct and concurrent validity, relationships between the Hinting Task and clinical, cognitive and functional measures were examined with correlational analyses (Pearson's $r$ ). For these analyses, the Hinting Task scores were logtransformed. Two-tailed tests were applied for all statistical analyses.

\section{Results}

\subsection{Internal consistency and ceiling effects}

Cronbach's $\alpha$ in the schizophrenia $(\alpha=0.76)$ and BD-I $(\alpha=0.72)$ groups approached a generally accepted level of internal consistency ( $\alpha=0.8$; Field, 2013), while the $\alpha$ in the healthy control group was lower $(\alpha=0.59)$. The estimated internal consistency in the BD-II group was also low $(\alpha=0.55)$ and biased by the exclusion of three items with zero variance. Removal of some items improved $\alpha$ in the schizophrenia group, but the exclusion of these items had a detrimental effect on the $\alpha$ in the other groups. Accordingly, no single item consistently improved $\alpha$ in all clinical groups if removed. Only one participant scored at ceiling in the schizophrenia group. In the other groups, however, substantial ceiling effects emerged: The BD-I group had $6(19.35 \%)$, the BD-II group had 7 (24.14\%) and the healthy control group had 44 participants $(24.04 \%)$ reaching maximum score.

\subsection{Group comparisons}

Between group comparisons are presented in Table 2 . The schizophrenia group $(M=$ $15.10, S D=3.56)$ displayed significantly lower scores on the Hinting Task than the BD-I group $(M=17.32, S D=2,66, p=.014, r=-.39)$, the BD-II group $(M=18.24, S D=1.62, p<$ 


\section{THE NORWEGIAN HINTING TASK}

$.001, r=-.55)$ and the healthy control group $(M=18.33, S D=1.68, p<.001, r=-.41)$. All other group differences on the Hinting Task were non-significant.

\subsection{Construct and concurrent validity}

Results from the analyses of construct and concurrent validity can be found in Table 3. Performance on the Hinting Task was significantly associated with PFA in the schizophrenia ( $p=.014$ ), but not the BD groups. Scores on the Hinting Task were significantly correlated with scores on MCCB in the schizophrenia and BD-I groups (both $p s=.006$ ). In addition, the Hinting Task was significantly negatively correlated with the PANSS negative factor $(p=$ $.025)$ and the PANSS disorganized factor $(p=.018)$ in the schizophrenia group. In contrast, no significant correlations were found between scores on the Hinting Task and clinical scales in the BD-I group. In the BD-II group, however, the Hinting Task was significantly negatively correlated with the PANSS disorganized factor $(p=.017)$. Concerning functional measures, the Hinting Task score was significantly positively correlated with scores on UPSA-B $(p=.010)$ in the schizophrenia group. No other significant correlations between the Hinting Task and functional measures were found across groups.

\section{Discussion}

\subsection{Internal consistency and ceiling effects}

The current study suggests that the Norwegian translation of the Hinting Task is comparable to the original version regarding internal consistency in schizophrenia and healthy control samples (Pinkham et al., 2016; 2018). A similar level of internal consistency has also been reported in FEP (Mallawaarachchi et al., 2019). In the present study, internal consistency in the BD-I group approached an acceptable level, in contrast to the BD-II group, where internal consistency was poor. The low estimates for the BD-II and healthy control groups are presumably related to the narrow range of scores in these groups. Substantial ceiling effects emerged in three of four groups. The proportion of scores at ceiling in the healthy control 


\section{THE NORWEGIAN HINTING TASK}

group was more than twice as large as in previous studies (Ludwig et al., 2017; Pinkham et al., 2016; 2018). These ceiling effects are presumably related to high IQs, young ages and short duration of illness across groups in the current study.

\subsection{Group comparisons}

As expected, the schizophrenia group performed significantly worse on the Hinting Task than both BD groups and the healthy control group. The effect size of the difference between the schizophrenia and healthy control group was $r=.41$. The effect size $r$ is a base-rate sensitive estimate (affected by dissimilar group sizes; McGrath \& Meyer, 2006). Thus, $r$ estimates of differences between clinical groups $(n=29-31)$ and the healthy control group $(n=183)$ in this study were deflated and interpreted in light of this. When adjusted for base-rate inequalities, $r$ $=.41$ is considered a large effect size (Cohen, 1992). This finding is in line with previous studies (Bora, Yucel, \& Pantelis, 2009; Corcoran \& Frith, 2003; Corcoran, Mercer, \& Frith, 1995; Pinkham et al., 2016).

Performance differences on the Hinting Task between schizophrenia and BD-I and schizophrenia and BD-II were medium-large $(r=.39)$ and large $(r=.55)$, respectively. Other studies that have compared schizophrenia and BD samples on the Hinting Task either found no difference (Donohoe et al., 2012; Thaler et al., 2013) or failed to report effect sizes (Lahera et al., 2015). However, as means and standard deviations of the schizophrenia and BD groups were provided in these studies, effect sizes of the differences can be calculated. All effect sizes were medium or small $(d=.64, d=.31, d=.27)$. High IQs and low levels of manic and depressive symptoms in the current BD sample compared to previous studies might partly explain this disparity.

The BD groups were not significantly different from the healthy control group on the Hinting Task, contrary to expectations. Effect size estimates revealed that the difference was greater between BD-I and healthy controls than between BD-II and healthy controls. In the 


\section{THE NORWEGIAN HINTING TASK}

meta-analyses by Samamé et al. (2015) and Bora et al. (2016), BD patients scored significantly lower than healthy controls on the Hinting Task (Hedge's $g=.45$ and $\mathrm{d}=.47$, respectively). Even though the difference between BD-I and healthy controls in the current study was non-significant, the effect size $(r=.14)$ was not very different from the effect size reported by Samamé et al. (2015) and Bora et al. (2016), if adjusted for base-rate inequalities (McGrath \& Meyer, 2006). All effect sizes are medium. With greater power in the present study the difference between BD-I and healthy controls might have become statistically significant. As predicted, the BD-I and BD-II groups did not differ significantly on the Hinting Task. While the Hinting Task is relatively undemanding, more complex ToM measures might be able to discriminate between BD subtypes.

\subsection{Construct and concurrent validity}

The Hinting Task and PFA were significantly correlated in the schizophrenia group. It was expected that these measures would be significantly, but not highly, correlated, given that ToM and emotion recognition are theoretically related, but separate domains of social cognition. Some factor analyses suggest that emotion recognition and ToM load on one factor (Browne et al., 2016; Buck, Healey, Gagen, Roberts, \& Penn, 2016; Lysaker et al., 2013), others do not (Mike et al., 2019). In the FEP study by Mallawaarachchi et al. (2019), the correlation between the Hinting task and facial emotion recognition was $r=.33$, slightly lower than our finding for schizophrenia $(r=.44)$. Mallawaarachchi et al. (2019) consider this finding to represent only a moderate degree of discriminant validity. We would argue that a correlation of this magnitude is expected, taking into account that both ToM and emotion recognition are social cognitive domains. In the $\mathrm{BD}$ groups, the correlations between the Hinting Task and PFA were weaker than expected. A reason might be the lack of variation in both Hinting Task and PFA scores in these groups (Goodwin \& Leech, 2006). 


\section{THE NORWEGIAN HINTING TASK}

As expected, scores on the Hinting Task were significantly correlated with MCCB in both the schizophrenia and BD-I groups. These variables were not, however, significantly related in the BD-II group, perhaps due to the narrow range of Hinting Task scores in this group (Goodwin \& Leech, 2006). The significant negative correlations between the Hinting Task and negative and disorganized symptoms in schizophrenia are in line with previous research (Fett, Maat, \& GROUP Investigators, 2013; Greig, Bryson, \& Bell, 2004; Ventura et al., 2013; Vohs et al., 2014). No significant correlations were found between manic symptoms and performance on the Hinting Task in the BD groups. However, a large majority of the BD sample scored below a recommended clinical cut-off (YMRS < 8; Tohen et al., 2009). Absence of a significant correlation might therefore be related to a restricted range of manic symptoms (Goodwin \& Leech, 2006).

No significant correlations were evident between depressive symptoms, measured with CDSS or PANSS depressive factor, and the Hinting Task in the BD groups, contrary to expectation. However, in the BD-II group both correlations were of a moderate size (both $r=$ 0.36). This suggests that Hinting Task performance may be related to depression in BD-II. In regards to the CDSS, it is possible that this measure did not accurately assess severity of bipolar depression. Psychometric evaluations suggest that the CDSS is more specific for assessment of depression in schizophrenia than other frequently used depression measures (Grover et al., 2017). Nevertheless, the level of depressive symptoms in the BD-I group was low, and only two patients had CDSS scores $>8$. The lack of significant correlations might therefore be related to a restricted range of depressive symptoms in this group (Goodwin \& Leech, 2006).

We expected performance on the Hinting Task to be significantly positively correlated with performance on measures of both functional capacity (UPSA-B) and social functioning (SFS) in the schizophrenia group. However, only the relationship with UPSA-B was 


\section{THE NORWEGIAN HINTING TASK}

significant. The association with functional capacity replicates findings from the SCOPE studies, but these studies also reported a significant correlation with social functioning (Pinkham et al., 2016; 2018). The SCOPE studies, however, employed an informant-rated measure of social functioning, not a self-report measure such as SFS. Nevertheless, other previous studies have investigated the association between the Hinting Task and SFS, and consistently reported strong, significant relationships (Bora, Eryavuz, Kayahan, Sungu, \& Veznedaroğlu, 2006; Brown, Tas, Can, Esen-Danaci, \& Brüne, 2014; Martínez-Domínguez, Penadés, Segura, González-Rodríguez, \& Catalán, 2015). Confounding factors, like social networks, personal resources and family support, in the current sample might explain the absence of a significant relationship between ToM and social functioning across groups. None of the correlations between functional outcome variables and the Hinting Task were significant in the BD groups. This finding is in line with other studies (Barrera et al., 2013; Lahera et al., 2015; Martino et al., 2011). More complex and ecologically valid ToM measures might be needed to consistently detect significant correlations between functioning and ToM in BD. Only a handful of studies have employed such measures in BD samples to date (Feyerabend et al., 2018; Lee et al., 2013; Montag et al., 2010; Rowland et al., 2013), and the relationships with functional outcome in BD populations have not yet been investigated.

\subsection{Conclusion}

Limitations of the study include small sample sizes for the clinical groups, that depression was assessed with an instrument more suitable for one clinical group (schizophrenia), and the lack of other ToM measures. The clinical groups were also heterogeneous in regard to age, symptoms, medication, age at onset and duration of illness. Accordingly, no conclusions can be drawn for specific subgroups of patients. 


\section{THE NORWEGIAN HINTING TASK}

In conclusion, the Norwegian version of the Hinting Task distinguished schizophrenia patients from BD patients and healthy controls, had adequate levels of internal consistency in the schizophrenia and BD-I groups, and was related to symptoms and functional capacity in the schizophrenia group. It did not discriminate between BD patients and healthy controls, was not related to BD symptoms or functional outcome variables in the BD groups. Finally, it showed poor internal consistency in the BD-II group and a clear ceiling effect in both BD groups. We consider the Norwegian version of the Hinting Task to be suitable for the assessment of ToM in individuals with schizophrenia. However, it may not be difficult enough to properly measure ToM across diagnoses in scientific studies. A possible solution to this problem is to adapt the test by including more difficult items with less clear hints (Marjoram et al., 2005). For now, caution is warranted when using the test for populations other than schizophrenia.

\section{Acknowledgement}

The authors are grateful to the participants for contributing their time and efforts and wish to thank the clinical and research personnel at NORMENT.

\section{Disclosure statement}

No potential conflict of interest was reported by the authors.

\section{Funding}

This work was supported by the South-Eastern Norway Regional Health Authority under grants \#2010007 and \# 2017069, and the Research Council of Norway under grant \#223273. 


\section{References}

Addington, D., Addington, J., \& Schissel, B. (1990). A depression rating scale for schizophrenics. Schizophrenia Research, 3(4), 247-251. http://doi.org/10.1016/09209964(90)90005-R

American Psychiatric Association. (2000). Diagnostic and statistical manual of mental disorders (DSM-IV®). Washington, DC: Author.

Baron-Cohen, S., Wheelwright, S., Hill, J., Raste, Y., \& Plumb, I. (2001). The "Reading the Mind in the Eyes" Test Revised Version: A Study with Normal Adults, and Adults with Asperger Syndrome or High-functioning Autism. Journal of Child Psychology and Psychiatry, 42(2), 241-251. http://doi.org/10.1111/1469-7610.00715

Barrera, Á., Vázquez, G., Tannenhaus, L., Lolich, M., \& Herbst, L. (2013). Theory of mind and functionality in bipolar patients with symptomatic remission. Revista De Psiquiatría Y Salud Mental (English Edition), 6(2), 67-74.

http://doi.org/10.1016/j.rpsmen.2012.07.003

Birchwood, M., Smith, J., Cochrane, R., Wetton, S., \& Copestake, S. (1990). The Social Functioning Scale. The development and validation of a new scale of social adjustment for use in family intervention programmes with schizophrenic patients. The British Journal of Psychiatry, 157, 853-859.

Bodnar, A., \& Rybakowski, J. K. (2017). Mentalization deficit in bipolar patients during an acute depressive and manic episode: association with cognitive functions. International Journal of Bipolar Disorders, 5, 1-9. http://doi.org/10.1186/s40345-017-0107-3

Bora, E., Bartholomeusz, C., \& Pantelis, C. (2016). Meta-analysis of Theory of Mind (ToM) impairment in bipolar disorder. Psychological Medicine, 46, 253-264. http://doi.org/10.1017/S0033291715001993 


\section{THE NORWEGIAN VERSION OF THE HINTING TASK}

Bora, E., Eryavuz, A., Kayahan, B., Sungu, G., \& Veznedaroğlu, B. (2006). Social functioning, theory of mind and neurocognition in outpatients with schizophrenia; mental state decoding may be a better predictor of social functioning than mental state reasoning. Psychiatry Research, 145(2-3), 95-103. http://doi.org/10.1016/j.psychres.2005.11.003

Bora, E., \& Pantelis, C. (2016). Social cognition in schizophrenia in comparison to bipolar disorder: A meta-analysis. Schizophrenia Research, 175(1-3), 72-78. http://doi.org/10.1016/j.schres.2016.04.018

Bora, E., Yucel, M., \& Pantelis, C. (2009). Theory of mind impairment in schizophrenia: Meta-analysis. Schizophrenia Research, 109(1-3), 1-9. http://doi.org/10.1016/j.schres.2008.12.020

Brown, E. C., Tas, C., Can, H., Esen-Danaci, A., \& Brüne, M. (2014). A closer look at the relationship between the subdomains of social functioning, social cognition and symptomatology in clinically stable patients with schizophrenia. Comprehensive Psychiatry, 55(1), 25-32. http://doi.org/10.1016/j.comppsych.2013.10.001

Browne, J., Penn, D. L., Raykov, T., Pinkham, A. E., Kelsven, S., Buck, B., \& Harvey, P. D. (2016). Social cognition in schizophrenia: Factor structure of emotion processing and theory of mind. Psychiatry Research, 242, 150-156.

http://doi.org/10.1016/j.psychres.2016.05.034

Brüne, M., \& Brüne-Cohrs, U. (2006). Theory of mind-evolution, ontogeny, brain mechanisms and psychopathology. Neuroscience \& Biobehavioral Reviews, 30(4), 437455. http://doi.org/10.1016/j.neubiorev.2005.08.001

Buck, B. E., Healey, K. M., Gagen, E. C., Roberts, D. L., \& Penn, D. L. (2016). Social cognition in schizophrenia: factor structure, clinical and functional correlates. Journal of Mental Health, 25(4), 330-337. http://doi.org/10.3109/09638237.2015.1124397

Cohen, J. (1992). A Power Primer. Psychological Bulletin, 112(1), 155-159. 


\section{THE NORWEGIAN VERSION OF THE HINTING TASK}

Corcoran, R., \& Frith, C. D. (2003). Autobiographical memory and theory of mind: evidence of a relationship in schizophrenia. Psychological Medicine, 33(5), 897-905. http://doi.org/10.1017/S0033291703007529

Corcoran, R., Mercer, G., \& Frith, C. D. (1995). Schizophrenia, symptomatology and social inference: Investigating "theory of mind" in people with schizophrenia. Schizophrenia Research, 17(1), 5-13. http://doi.org/10.1016/0920-9964(95)00024-G

Davidson, C. A., Lesser, R., Parente, L. T., \& Fiszdon, J. M. (2017). Psychometrics of social cognitive measures for psychosis treatment research. Schizophrenia Research, 193, 1-7. http://doi.org/10.1016/j.schres.2017.06.018

Donohoe, G., Duignan, A., Hargreaves, A., Morris, D. W., Rose, E., Robertson, D., . . . Corvin, A. (2012). Social cognition in bipolar disorder versus schizophrenia: comparability in mental state decoding deficits. Bipolar Disorders, 14(7), 743-748. http://doi.org/10.1111/bdi.12011

Durlak, J. A. (2009). How to Select, Calculate, and Interpret Effect Sizes. Journal of Pediatric Psychology, 34(9), 917-928. http://doi.org/10.1093/jpepsy/jsp004

Fett, A. K. J., Maat, A., \& GROUP Investigators. (2013). Social Cognitive Impairments and Psychotic Symptoms: What Is the Nature of Their Association? Schizophrenia Bulletin, 39(1), 77-85. http://doi.org/10.1093/schbul/sbr058

Fett, A.-K. J., Viechtbauer, W., Dominguez, M.-D.-G., Penn, D. L., van Os, J., \& Krabbendam, L. (2011). The relationship between neurocognition and social cognition with functional outcomes in schizophrenia: A meta-analysis. Neuroscience \& Biobehavioral Reviews, 35(3), 573-588. http://doi.org/10.1016/j.neubiorev.2010.07.001

Feyerabend, J., Lüttke, S., Grosse-Wentrup, F., Wolter, S., Hautzinger, M., \& Wolkenstein, L. (2018). Theory of mind in remitted bipolar disorder: Younger patients struggle in tasks of 


\section{THE NORWEGIAN VERSION OF THE HINTING TASK}

higher ecological validity. Journal of Affective Disorders, 231, 32-40. http://doi.org/10.1016/j.jad.2018.01.026

Field, A. (2013). Discovering statistics using IBM SPSS statistics. London: SAGE.

First, M., Spitzer, R., Gibbon, M., \& Williams, J. (1997). Structural Clinical Interview for DSM-IV Axis I Disorders - Clinician Version (SCID-CV). DC: Washington: American Psychiatric Press.

Frommann, N., Streit, M., \& Wölwer, W. (2003). Remediation of facial affect recognition impairments in patients with schizophrenia: a new training program. Psychiatry Research, 117(3), 281-284. http://doi.org/10.1016/S0165-1781(03)00039-8

Goodwin, L. D., \& Leech, N. L. (2006). Understanding Correlation: Factors That Affect the Size of r. The Journal of Experimental Education, 74(3), 249-266. http://doi.org/10.3200/JEXE.74.3.249-266

Green, M. F., Penn, D. L., Bentall, R., Carpenter, W. T., Gaebel, W., Gur, R. C., . . Heinssen, R. (2008). Social Cognition in Schizophrenia: An NIMH Workshop on Definitions, Assessment, and Research Opportunities. Schizophrenia Bulletin, 34(6), 1211-1220. http://doi.org/10.1093/schbul/sbm145

Greig, T. C., Bryson, G. J., \& Bell, M. D. (2004). Theory of Mind Performance in Schizophrenia: Diagnostic, Symptom, and Neuropsychological Correlates. The Journal of Nervous and Mental Disease, 192(1), 12-18. http://doi.org/10.1097/01.nmd.0000105995.67947.fc

Grover, S., Sahoo, S., Dua, D., Chakrabarti, S., \& Avasthi, A. (2017). Scales for assessment of depression in schizophrenia: Factor analysis of calgary depression rating scale and hamilton depression rating scale. Psychiatry Research, 252, 333-339. http://doi.org/10.1016/j.psychres.2017.03.018 


\section{THE NORWEGIAN VERSION OF THE HINTING TASK}

Hawken, E. R., Harkness, K. L., Lazowski, L. K., Summers, D., Khoja, N., Gregory, J. G., \& Milev, R. (2016). The manic phase of Bipolar disorder significantly impairs theory of mind decoding. Psychiatry Research, 239, 275-280.

http://doi.org/10.1016/j.psychres.2016.03.043

Hellvin, T., Sundet, K., Vaskinn, A., Simonsen, C., Ueland, T., Andreassen, O. A., \& Melle, I. (2010). Validation of the Norwegian version of the Social Functioning Scale (SFS) for schizophrenia and bipolar disorder. Scandinavian Journal of Psychology, 51(6), 525-533. http://doi.org/10.1111/j.1467-9450.2010.00839.x

Holmén, A., Juuhl-Langseth M., Thormodsen, R., Melle, I., Rund, B.R. (2010).

Neuropsychological profile in early onset schizophrenia-spectrum disorders: measured with the MATRICS battery. Schizophrenia Bulletin, 36(4), 852-859.

Ioannidi, N., Konstantakopoulos, G., Sakkas, D., \& Oulis, P. (2015). The relationship of Theory of Mind with symptoms and cognitive impairment in bipolar disorder: a prospective study. Psychiatriki, 26(1), 17-27.

Kay, S. R., Fiszbein, A., \& Opler, L. A. (1987). The positive and negative syndrome scale (PANSS) for schizophrenia. Schizophrenia Bulletin, 13(2), 261-276.

Lahera, G., Herrera, S., Reinares, M., Benito, A., Rullas, M., González-Cases, J., \& Vieta, E. (2015). Hostile attributions in bipolar disorder and schizophrenia contribute to poor social functioning. Acta Psychiatrica Scandinavica, 131(6), 472-482. http://doi.org/10.1111/acps.12399

Lee, J., Altshuler, L., Glahn, D. C., Miklowitz, D. J., Ochsner, K., \& Green, M. F. (2013). Social and Nonsocial Cognition in Bipolar Disorder and Schizophrenia: Relative Levels of Impairment. American Journal of Psychiatry, 170(3), 334-341. http://doi.org/10.1176/appi.ajp.2012.12040490 


\section{THE NORWEGIAN VERSION OF THE HINTING TASK}

Ludwig, K. A., Pinkham, A. E., Harvey, P. D., Kelsven, S., \& Penn, D. L. (2017). Social cognition psychometric evaluation (SCOPE) in people with early psychosis: A preliminary study. Schizophrenia Research, 190, 1-8. http://doi.org/10.1016/j.schres.2017.03.001

Lysaker, P. H., Gumley, A., Luedtke, B., Buck, K. D., Ringer, J. M., Olesek, K., . . . Dimaggio, G. (2013). Social cognition and metacognition in schizophrenia: evidence of their independence and linkage with outcomes. Acta Psychiatrica Scandinavica, 127(3), 239-247. http://doi.org/10.1111/acps.12012

Mallawaarachchi, S. R., Cotton, S. M., Anderson, J., Killackey, E., \& Allott, K. A. (2019). Exploring the use of the Hinting Task in first-episode psychosis. Cognitive neuropsychiatry, 24(1), 65-79. https://doi.org/10.1080/13546805.2019.1568864

Marjoram, D., Gardner, C., Burns, J., Miller, P., Lawrie, S., \& Johnstone, E. (2005). Symptomatology and social inference: A theory of mind study of schizophrenia and psychotic affective disorder. Cognitive Neuropsychiatry, 10(5), 347-359. http://doi.org/10.1080/13546800444000092

Martino, D. J., Strejilevich, S. A., Fassi, G., Marengo, E., \& Igoa, A. (2011). Theory of mind and facial emotion recognition in euthymic bipolar I and bipolar II disorders. Psychiatry Research, 189(3), 379-384. http://doi.org/10.1016/j.psychres.2011.04.033

Martínez-Domínguez, S., Penadés, R., Segura, B., González-Rodríguez, A., \& Catalán, R. (2015). Influence of social cognition on daily functioning in schizophrenia: Study of incremental validity and mediational effects. Psychiatry Research, 225(3), 374-380. http://doi.org/10.1016/j.psychres.2014.12.011

Mausbach, B. T., Harvey, P. D., Goldman, S. R., Jeste, D. V., \& Patterson, T. L. (2006). Development of a Brief Scale of Everyday Functioning in Persons with Serious Mental Illness. Schizophrenia Bulletin, 33(6), 1364-1372. http://doi.org/10.1093/schbul/sbm014 
THE NORWEGIAN VERSION OF THE HINTING TASK

McDonald, S., Flanagan, S., Rollins, J., \& Kinch, J. (2003). TASIT: A new clinical tool for assessing social perception after traumatic brain injury. The Journal of Head Trauma Rehabilitation, 18(3), 219-238.

McGrath, R. E., \& Meyer, G. J. (2006). When effect sizes disagree: The case of $\mathrm{r}$ and d. Psychological Methods, 11(4), 386-401. http://doi.org/10.1037/1082-989X.11.4.386

Mike, L., Guimond, S., Kelly, S., Thermenos, H., Mesholam-Gately, R., Eack, S., \& Keshavan, M. (2019). Social cognition in early course of schizophrenia: Exploratory factor analysis. Psychiatry Research, 272, 737-743.

https://doi.org/10.1016/j.psychres.2018.12.152

Mitchell, R. L. C., \& Young, A. H. (2016). Theory of Mind in Bipolar Disorder, with Comparison to the Impairments Observed in Schizophrenia. Frontiers in Psychiatry, 6(5), 1211-21. http://doi.org/10.3389/fpsyt.2015.00188

Montag, C., Ehrlich, A., Neuhaus, K., Dziobek, I., Heekeren, H. R., Heinz, A., \& Gallinat, J. (2010). Theory of mind impairments in euthymic bipolar patients. Journal of Affective Disorders, 123(1-3), 264-269. http://doi.org/10.1016/j.jad.2009.08.017

Nuechterlein, K. H., Barch, D. M., Gold, J. M., Goldberg, T. E., Green, M. F., \& Heaton, R. K. (2004). Identification of separable cognitive factors in schizophrenia. Schizophrenia Research, 72(1), 29-39. http://doi.org/10.1016/j.schres.2004.09.007

Pinkham, A. E., Harvey, P. D., \& Penn, D. L. (2018). Social Cognition Psychometric Evaluation: Results of the Final Validation Study. Schizophrenia Bulletin, 44(4), 737748. http://doi.org/10.1093/schbul/sbx117

Pinkham, A. E., Penn, D. L., Green, M. F., \& Harvey, P. D. (2016). Social Cognition Psychometric Evaluation: Results of the Initial Psychometric Study. Schizophrenia Bulletin, 42(2), 494-504. http://doi.org/10.1093/schbul/sbv056 


\section{THE NORWEGIAN VERSION OF THE HINTING TASK}

Pinkham, A. E., Penn, D. L., Green, M. F., Buck, B., Healey, K., \& Harvey, P. D. (2014). The Social Cognition Psychometric Evaluation Study: Results of the Expert Survey and RAND Panel. Schizophrenia Bulletin, 40(4), 813-823. http://doi.org/10.1093/schbul/sbt081

Roberts, D. L., \& Penn, D. L. (2009). Social cognition and interaction training (SCIT) for outpatients with schizophrenia: A preliminary study. Psychiatry Research, 166(2-3), 141147. http://doi.org/10.1016/j.psychres.2008.02.007

Rowland, J. E., Hamilton, M. K., Vella, N., Lino, B. J., Mitchell, P. B., \& Green, M. J. (2013). Adaptive Associations between Social Cognition and Emotion Regulation are Absent in Schizophrenia and Bipolar Disorder. Frontiers in Psychology, 3, 607. http://doi.org/10.3389/fpsyg.2012.00607

Samamé, C., Martino, D. J., \& Strejilevich, S. A. (2015). An individual task meta-analysis of social cognition in euthymic bipolar disorders. Journal of Affective Disorders, 173, 146153. http://doi.org/10.1016/j.jad.2014.10.055

Savla, G. N., Vella, L., Armstrong, C. C., Penn, D. L., \& Twamley, E. W. (2013). Deficits in Domains of Social Cognition in Schizophrenia: A Meta-Analysis of the Empirical Evidence. Schizophrenia Bulletin, 39(5), 979-992. http://doi.org/10.1093/schbul/sbs080

Sprong, M., Schothorst, P., Vos, E., Hox, J., \& Van Engeland, H. (2007). Theory of mind in schizophrenia: Meta-analysis. The British Journal of Psychiatry, 191(1), 5-13. http://doi.org/10.1192/bjp.bp.107.035899

Thaler, N. S., Allen, D. N., Sutton, G. P., Vertinski, M., \& Ringdahl, E. N. (2013). Differential impairment of social cognition factors in bipolar disorder with and without psychotic features and schizophrenia. Journal of Psychiatric Research, 47(12), 20042010. http://doi.org/10.1016/j.jpsychires.2013.09.010 


\section{THE NORWEGIAN VERSION OF THE HINTING TASK}

Tohen, M., Frank, E., Bowden, C. L., Colom, F., Ghaemi, S. N., Yatham, L. N., . . Berk, M. (2009). The International Society for Bipolar Disorders (ISBD) Task Force report on the nomenclature of course and outcome in bipolar disorders. Bipolar Disorders, 11(5), 453473. http://doi.org/10.1111/j.1399-5618.2009.00726.x

Ventura, J., Wood, R. C., \& Hellemann, G. S. (2013). Symptom Domains and Neurocognitive Functioning Can Help Differentiate Social Cognitive Processes in Schizophrenia: A Meta-Analysis. Schizophrenia Bulletin, 39(1), 102-111. http://doi.org/10.1093/schbul/sbr067

Vlad, M., Raucher-Chéné, D., Henry, A., \& Kaladjian, A. (2018). Functional outcome and social cognition in bipolar disorder: Is there a connection? European Psychiatry, 52, 116125. http://doi.org/10.1016/j.eurpsy.2018.05.002

Vohs, J. L., Lysaker, P. H., Francis, M. M., Hamm, J., Buck, K. D., Olesek, K., . . Breier, A. (2014). Metacognition, social cognition, and symptoms in patients with first episode and prolonged psychoses. Schizophrenia Research, 153(1-3), 54-59. http://doi.org/10.1016/j.schres.2014.01.012

Wallwork, R. S., Fortgang, R., Hashimoto, R., Weinberger, D. R., \& Dickinson, D. (2012). Searching for a consensus five-factor model of the Positive and Negative Syndrome Scale for schizophrenia. Schizophrenia Research, 137(1-3), 246-250.

http://doi.org/10.1016/j.schres.2012.01.031

Wechsler, D. (2007). Wechsler Abbreviated Scale of Intelligence (WASI). Norwegian manual supplement. Stockholm: Pearson Assessment.

Young, R. C., Biggs, J. T., Ziegler, V. E., \& Meyer, D. A. (1978). A rating scale for mania: Reliability, validity and sensitivity. The British Journal of Psychiatry, 133, 429-435. 
THE NORWEGIAN VERSION OF THE HINTING TASK

Table 1. Demographics \& clinical characteristics.

\begin{tabular}{|c|c|c|c|c|c|c|c|}
\hline & $\begin{array}{c}\mathrm{SZ} \\
(\mathrm{n}=30)\end{array}$ & $\begin{array}{c}\text { BD-I } \\
(\mathrm{n}=31)\end{array}$ & $\begin{array}{c}\text { BD-II } \\
(\mathrm{n}=29)\end{array}$ & $\begin{array}{c}\mathrm{HC} \\
(\mathrm{n}=183)\end{array}$ & Statistics & $\mathrm{p}$ & Post hoc analysis \\
\hline \multicolumn{8}{|l|}{ Demographics } \\
\hline Gender, male, n (\%) & $18(60.00)$ & $14(45.16)$ & $11(37.93)$ & $102(55.74)$ & $\chi^{2}(3)=4.55$ & .208 & \\
\hline Age, years, Md (Range) & $27(19-59)$ & $30(19-63)$ & $29(18-53)$ & $34(18-55)$ & $H(3)=2.46$ & .483 & \\
\hline Education, years, Md (Range) & $12(9-18)$ & $15(10-17)$ & $13(9-18)$ & $15(10-20)$ & $H(3)=37.44$ & $<.001$ & $\mathrm{SZ}<\mathrm{BD}-\mathrm{I}, \mathrm{HC} ; \mathrm{BD}-\mathrm{II}<\mathrm{HC}$ \\
\hline NART, $M(S D)^{a}$ & $21.83(8.67)$ & $18.10(7.42)$ & $16.73(8.66)$ & $15.65(7.09)$ & $F(3)=6.29$ & $<.001$ & $\mathrm{HC}<\mathrm{SZ}$ \\
\hline WASI IQ, M (SD) & $102.0(13.9)$ & $111.8(10.6)$ & $113.2(9.1)$ & $115.9(9.2)$ & $F(3,57.70)=10.14$ & $<.001$ & $\mathrm{SZ}<\mathrm{BD}-\mathrm{I}, \mathrm{BD}-\mathrm{II}, \mathrm{HC}$ \\
\hline \multicolumn{8}{|l|}{ Clinical scales } \\
\hline PANSS Pos, Md (Range) & $9.5(4-17)$ & $5(4-8)$ & $4(4-9)$ & & $H(2)=46.15$ & $<.001$ & BD-I, BD-II < SZ \\
\hline PANSS Neg, Md (Range) & $14(7-27)$ & $7(6-16)$ & $7(6-20)$ & & $H(2)=32.89$ & $<.001$ & BD-I, BD-II < SZ \\
\hline PANSS Dis, Md (Range) & $6(3-11)$ & $3(3-7)$ & $3(3-6)$ & & $H(2)=22.23$ & $<.001$ & BD-I, BD-II < SZ \\
\hline PANSS Exc, Md (Range) & $5(4-12)$ & $5(4-8)$ & $4(4-8)$ & & $H(2)=4.56$ & .102 & \\
\hline PANSS Dep, M (SD) & $7.70(2.64)$ & $7.19(2.63)$ & $8.55(2.56)$ & & $F(2)=2.06$ & .133 & \\
\hline YMRS, Md (Range) ${ }^{\mathrm{b}}$ & $2(0-12)$ & $1(0-10.3)$ & $2(0-15)$ & & $H(2)=1.68$ & .432 & \\
\hline CDSS, Md (Range) & $2.5(0-14)$ & $3.0(0-16)$ & $7.0(0-17)$ & & $H(2)=4.79$ & .091 & \\
\hline GAF-S, M (SD) & $52.73(12.30)$ & $64.84(9.53)$ & $60.59(9.83)$ & & $F(2)=10.15$ & $<.001$ & SZ < BD-I, BD-II \\
\hline GAF-F, Md (Range) ${ }^{c}$ & $46.5(35-85)$ & $65(43-85)$ & $60.50(40-78)$ & & $H(2)=20.08$ & $<.001$ & SZ < BD-I, BD-II \\
\hline \multicolumn{8}{|l|}{ Illness course } \\
\hline AAO, Md (Range) & $24(7-43)$ & $21(15-49)$ & $20(11-42)$ & & $H(2)=3.66$ & .161 & \\
\hline DOI, Md (Range) & $4(0-44)$ & $6(0-44)$ & $8(0-35)$ & & $H(2)=4.05$ & .132 & \\
\hline \multicolumn{8}{|l|}{ Medication, n (\%) } \\
\hline Antipsychotics & $23(76.67)$ & $11(35.48)$ & $10(34.48)$ & & $\chi^{2}(2)=13.90$ & .001 & BD-I, BD-II < SZ \\
\hline Antiepileptics & $1(3.33)$ & $5(16.13)$ & $12(41.38)$ & & $\chi^{2}(2)=13.78$ & .001 & $\mathrm{SZ}<\mathrm{BD}-\mathrm{II}$ \\
\hline Lithium & $0(0)$ & $6(19.35)$ & $2(6.90)$ & & $\chi^{2}(2)=7.26$ & .026 & \\
\hline Antidepressants & $4(13.33)$ & $6(19.35)$ & $8(27.59)$ & & $\chi^{2}(2)=1.89$ & .390 & \\
\hline
\end{tabular}

AAO = Age at onset, BD-I = Bipolar I disorder, BD-II = Bipolar II disorder, CDSS = Calgary Depression Scale for Schizophrenia, DOI = Duration of illness, GAF-F = Global Assessment of Functioning - Functioning, GAF-S = Global Assessment of Functioning - Symptoms, HC = Healthy controls, M = Mean, NART = National Adult Reading Test, PANSS = Positive and Negative Syndrome Scale for Schizophrenia, SZ = Schizophrenia, SD = Standard deviation, YMRS = Young Mania Rating Scale.

$\mathrm{a}=$ NART (number of incorrect answers) missing scores: $\mathrm{BD}-\mathrm{II}=3, \mathrm{~b}=$ YMRS missing scores: $\mathrm{SZ}=3, \mathrm{BD}-\mathrm{I}=1, \mathrm{c}=\mathrm{GAF}-\mathrm{F}$ missing scores: BD-II $=1$. 
Table 2. Group comparisons on social cognitive, neurocognitive and functional measures.

\begin{tabular}{|c|c|c|c|c|c|c|c|}
\hline & $\begin{array}{c}\mathrm{SZ} \\
(\mathrm{n}=30)\end{array}$ & $\begin{array}{c}\text { BD-I } \\
(\mathrm{n}=31)\end{array}$ & $\begin{array}{l}\text { BD-II } \\
(n=29)\end{array}$ & $\begin{array}{c}\mathrm{HC} \\
(\mathrm{n}=183)\end{array}$ & Statistics & $\mathrm{p}$ & Post hoc analysis \\
\hline $\begin{array}{l}\text { Hinting, } \\
\text { Md (Range) }\end{array}$ & $16(4-20)$ & $18(9-20)$ & $19(15-20)$ & $19(12-20)$ & $\begin{array}{c}H(3)= \\
37.24\end{array}$ & $<0.001$ & $\begin{array}{c}\mathrm{SZ}<\mathrm{BD}-\mathrm{I}, \mathrm{BD}-\mathrm{II}, \\
\mathrm{HC}\end{array}$ \\
\hline $\begin{array}{l}\text { PFA, M } \\
(\text { SD) }\end{array}$ & $\begin{array}{c}77.57 \\
(10.31)\end{array}$ & $81.70(9.70)$ & $82.14(8.24)$ & $82.82(7.50)$ & $F(3)=3.57$ & 0.015 & $\mathrm{SZ}<\mathrm{HC}$ \\
\hline $\begin{array}{l}\text { MCCB, Md } \\
\text { (Range) }\end{array}$ & $\begin{array}{c}41.56(28.67 \\
-55.4)\end{array}$ & $\begin{array}{c}45.33(37.11 \\
-59.33)\end{array}$ & $\begin{array}{c}50.33(35.44 \\
-60.89)\end{array}$ & $\begin{array}{c}51.00(32.89 \\
-68.67)\end{array}$ & $\begin{array}{c}H(3)= \\
43.65\end{array}$ & $<0.001$ & $\begin{array}{c}\mathrm{SZ}<\mathrm{BD}-\mathrm{II}, \mathrm{HC} ; \\
\mathrm{BD}-\mathrm{I}<\mathrm{HC}\end{array}$ \\
\hline $\begin{array}{l}\text { UPSA-B, } \\
\text { Md (Range) }\end{array}$ & $\begin{array}{l}81.50(59- \\
94)\end{array}$ & $86(64-100)$ & $89(67-100)$ & - & $\begin{array}{c}H(2)= \\
14.10\end{array}$ & .001 & $\mathrm{SZ}<\mathrm{BD}-\mathrm{II}$ \\
\hline $\begin{array}{l}\text { SFS, M } \\
(\mathrm{SD})^{\mathrm{b}}\end{array}$ & $\begin{array}{l}105.32 \\
(9.83)\end{array}$ & $\begin{array}{l}114.15 \\
(6.37)\end{array}$ & $\begin{array}{l}108.20 \\
(9.01)\end{array}$ & $\begin{array}{l}123.66 \\
(5.60)\end{array}$ & $\begin{array}{l}F(3,53.60) \\
\quad=67.14\end{array}$ & $<.001$ & $\begin{array}{c}\mathrm{SZ}, \mathrm{BD}-\mathrm{II}<\mathrm{BD}-\mathrm{I} \\
<\mathrm{HC}\end{array}$ \\
\hline
\end{tabular}

BD-I = Bipolar I disorder, BD-II = Bipolar II disorder, Hinting $=$ The Hinting Task, MCCB = MATRICS Consensus Cognitive Battery, $\mathrm{Md}=$ Median, $\mathrm{M}=$ Mean, $\mathrm{PFA}=$ Pictures of Facial Affect test, $\mathrm{SD}=$ Standard deviation, $\mathrm{SFS}=\mathrm{Social}$ Functioning Scale, SZ = Schizophrenia, UPSA-B = Brief University of California San Diego (UCSD) Performance-based Skills Assessment.

$\mathrm{a}=$ PFA missing scores: $\mathrm{BD}-\mathrm{I}=1, \mathrm{~b}=\mathrm{SFS}$ missing scores: $\mathrm{SZ}=2$. 


\section{THE NORWEGIAN VERSION OF THE HINTING TASK}

Table 3. Correlations between the Hinting Task and cognitive, clinical and functional measures.

\begin{tabular}{|c|c|c|c|c|c|c|c|c|c|c|c|}
\hline & PFA & $\begin{array}{c}\text { MCCB } \\
\text { Composite }\end{array}$ & $\begin{array}{l}\text { PANSS } \\
\text { Positive }\end{array}$ & $\begin{array}{c}\text { PANSS } \\
\text { Negative }\end{array}$ & $\begin{array}{c}\text { PANSS } \\
\text { Disorganized }\end{array}$ & $\begin{array}{l}\text { PANSS } \\
\text { Excited }\end{array}$ & $\begin{array}{c}\text { PANSS } \\
\text { Depressed }\end{array}$ & YMRS & CDSS & UPSA-B & $\begin{array}{c}\text { SFS } \\
\text { Composite }\end{array}$ \\
\hline \multicolumn{12}{|l|}{ SZ } \\
\hline Hinting & $.442 *$ & $.492 * *$ & -.251 & $-.408 *$ & $-.429 *$ & -.306 & .026 & -.189 & -.067 & $.462 *$ & -.046 \\
\hline \multicolumn{12}{|l|}{ BD-I } \\
\hline Hinting & .279 & $.479 * *$ & .010 & -.073 & -.033 & .083 & .225 & -.020 & .081 & .111 & .051 \\
\hline \multicolumn{12}{|l|}{ BD-II } \\
\hline Hinting & -.026 & .128 & -.044 & .126 & $-.439 *$ & -.145 & -.363 & -.107 & -.359 & .290 & .337 \\
\hline
\end{tabular}

SZ = Schizophrenia, BD-I = Bipolar I disorder, BD-II = Bipolar II disorder, CDSS = Calgary Depression Scale for Schizophrenia, PFA = Pictures of Facial Affect test, Hinting = The Hinting Task, MCCB = MATRICS Consensus Cognitive Battery, PANSS = Positive and Negative Syndrome Scale for Schizophrenia, SFS = Social Functioning Scale, SZ = Schizophrenia, UPSA-B $=$ Brief University of California San Diego (UCSD) Performance-based Skills Assessment, YMRS = Young Mania Rating Scale.

$* \mathrm{p}<0.05, * * \mathrm{p}<0.01$ 